\title{
PRÁTICAS DE ESTRANHAMENTO, INDIGNAÇÃO E RESISTÊNCIA
}

\author{
Cecília Maria Bouças Coimbra
}

Resumo: O presente texto aponta algumas das importantes contribuições trazidas por Maria Helena Souza Patto para a Psicologia e a Educação em nosso país, em especial através de seu último livro, Exercícios de Indignação. Afirma-se ali não só a pesquisadora competente e cuidadora, a professora requisitada e respeitada, mas também a mulher solidária, amiga, acolhedora e indignada que indaga, estranha e coloca em análise o que vem sendo considerado como natural. São muitas e múltiplas Marias aqui apresentadas por uma de suas alunas da Pós-graduação da USP em 1988. Em especial toma relevo neste texto a prática cotidiana da resistência que os escritos de Maria Helena enfatizam. Resistência não como simples reação, mas como criação, produção de rupturas e afirmação de outras lógicas, de outras realidades. Essa é uma das múltiplas Marias aqui presentes.

Palavras-chave: Resistência. Psicologia e Educação. Multiplicidades. Indignação.

Cada luta se desenvolve em torno de um foco particular de poder... E se designar os focos, denunciá-los, falar deles publicamente é uma luta, não é porque ninguém ainda tinha tido consciência disto, mas porque falar a esse respeito - forçar a rede de informação institucional, nomear, dizer quem fez, o que fez, designar o alvo - é uma primeira inversão de poder, é um primeiro passo para outras lutas contra o poder. (Foucault, 1979, pp. 75-76) 
Falar de Maria Helena Souza Patto, de suas importantes contribuições para a Psicologia e a Educação, em especial de seu último e belíssimo livro Exercícios de Indignação (Patto, 2010) é para mim um desafio, uma tarefa de enorme responsabilidade. Isso porque não é falar somente sobre a pesquisadora competente e cuidadosa, a professora requisitada e respeitada, mas também olhar para a mulher solidária, sensível e acolhedora que sabe ser doce e amiga, mas que, quando necessário, com sua indignação e força indaga, estranha, coloca em análise o que é considerado como certo, como dado, como natural.

Essas várias e múltiplas Marias se fazem presentes em seus escritos, em suas aulas, em suas palestras, em seus diferentes encontros e têm uma característica em comum: a crítica ética-política às práticas escolares, ainda hoje hegemônicas, que classificam, rotulam, estigmatizam, discriminam, inferiorizam, normatizam e produzem os "fracassados" na escola.

Há mais de 25 anos, com a publicação de Psicologia e Ideologia: uma introdução crítica à Psicologia Escolar (Patto, 1984), Maria Helena, com a coragem que lhe é peculiar, afirmava outro modo de fazer psicologia na escola. Anos depois, com A produção do fracasso escolar (Patto, 1990) - sua tese de livre docência e obra fundamental e imprescindível para se entender historicamente como se vai forjando no Brasil uma certa identidade de "psicólogo escolar"-, nos mostra a "miséria do cotidiano da escola fundamental brasileira e sua relação com uma [certa] política educacional". Política dita científica, dentro dos marcos positivistas, cartesianos e tecnicistas e que, por isso, se considera neutra e objetiva. Diferenciando-se desta "ditadura do pensamento único", Maria Helena nos fala dos "tempos sombrios do capitalismo atual", mas nos deixa "aberta a fresta da resistência",como ela mesma afirma na Introdução de seus Exercícios de Indignação.

Formada nos anos 1960, essa Maria múltipla e diversa - imersa em um contexto onde se naturalizava a teoria da carência e privação culturais para os segmentos pobres de nossa população - não se deixou iludir, não se deixou levar. Vivendo algum tempo em solo norte-americano, de onde essas teorias foram importadas, Maria Helena percebeu os engodos, as capturas, as armadilhas que essas caracterizações essencialistas da pobreza produziam nos educadores em geral e nos profissionais que com eles trabalhavam, em especial nos psicólogos. Corajosamente estranha e desnaturaliza tais enfoques individualizantes, em que a carência e a privação se fazem presentes produzindo sujeitos fracassados em constante e permanente falta.

Conheci pessoalmente Maria Helena Souza Patto quando fiz meu doutorado na Universidade de São Paulo, em 1988. Já bebia de seus escritos e com eles me encantava, neles procurava embasamento para meu trabalho como psicóloga na Secretaria Municipal de Educação do Rio de Janeiro naqueles anos. 
Foi dela que ouvi pela primeira vez a expressão"pequenos assassinatos cotidianos", que muito me afetou. Assassinatos que cometemos através de nossas práticas diárias ao produzirmos com nossas escutas, entrevistas, testes, laudos e relatórios sujeitos faltosos, famílias desestruturadas... Discursos de verdade, sentenças de morte, pois enunciados por especialistas que dizem atuar objetiva e neutramente. Discursos de verdade, porque científicos, conferindo a quem os enuncia um poder de vida e de morte sobre os demais mortais. A "violência técnica", como já nos mostrava Franco Basaglia (1985), está presente nas práticas dos chamados especialistas, quando lhes é delegado o pleno saber sobre a vida como modo de enquadramento dela nos registros dominantes. Esses especialistas, como os psicólogos na escola, têm sido convocados para atenuar conflitos, dobrar as resistências e eliminar as diferenças tão repudiadas pelo mundo capitalista. Com suas "técnicas reparadoras" mascaram a violência embutida em suas práticas limitando-se a consentir que se fortaleça e se perpetue uma violência cruel e global: a de condenar as diferenças, esmagá-las, moldá-las pelas mãos do instituído. Sua tarefa, entendida como "terapêutico-orientadora", tem sido de adaptação dos sujeitos aos padrões dominantes e de aceitação de sua condição de "objetos de violência". Nos informa, ainda, Basaglia que:

\footnotetext{
O papel dessas figuras intermediárias será, portanto, mistificar a violência através do tecnicismo, sem com isso modificar sua natureza, mas fazendo com que o objeto da violência se adapte à violência de que é o objeto sem sequer chegar a ter consciência dela e sem poder, com isso, reagir a ela tornando-se, por sua vez, violento. A função dos novos prepostos será ampliar as fronteiras da exclusão descobrindo, tecnicamente, novas formas de infração que tinham sido consideradas normais até então. (Basaglia, 1985, p. 102)
}

Entretanto, ao estranhar as naturalizações, ao indignar-se diante desses pequenos e invisibilizados "assassinatos cotidianos", nossa querida amiga não fica somente no território da denúncia, nos sentimentos reativos. Ela se abre e aponta para os movimentos de resistência, para a construção de outros possíveis.

Diferentemente do que nos tem sido ensinado, que a resistência seria efeito do poder, entendemos, como Foucault (1982) e Deleuze (2002), que o poder funciona, justamente, para responder aos movimentos de resistência, aqui entendidos enquanto afirmação de processos inéditos de vida. O poder cria normas, medidas, identidades que tentam fragilizar, manietar e, mesmo, capturar o que pode se tornar perigoso: a afirmação de "novas formas de relações, novas formas de amor e novas formas de criação" (Foucault, 1982, p. 1).

As normas, as medidas, as identidades passam a ser condição de pertencimento ao mundo capitalista. A sua aceitação, a submissão a elas 
é a garantia de se ter um lugar ao sol; é o preço que se paga para que se possa ser considerado e reconhecido como um cidadão integrado, um cidadão produtivo, um cidadão participativo.

Continuando suas anotações sobre a questão da resistência, Foucault nos diz que "se não há resistência, não há relações de poder... $\mathrm{A}$ resistência vem em primeiro lugar, e ela permanece superior a todas as forças do processo, seu efeito obriga a mudarem as relações de poder" (Foulcault, 1982, p.6).

Entendemos, assim, que resistir não é simplesmente se opor.É algo muito mais difícil: é criar, é produzir rupturas, é afirmar outras lógicas, outras realidades. Diferentemente, os poderes e o Estado buscam a organização, a ordenação, a hierarquização, a homogeneização das diferenças e das multiplicidades. Portanto, resistir é não permanecer nas possibilidades dadas, é não render-se a um estado de coisas já estabelecido, no qual nos satisfazemos nestes tempos neoliberais de "democracia participativa" com o que nos dizem ser o possível hoje. É, diferentemente, criar possibilidades inéditas, ações fora das medidas, inventar valores novos diferentes dos instituídos; é ir além desses valores dados: é transvalorar, como nos ensina Nietzsche. É, portanto, a afirmação vigorosa do novo, da imanência da criação. Não a aposta em um outro mundo futuro, em uma possível transcendência, mas uma afirmação no aqui e agora, na criação/experimentação de caminhos que se fazem no próprio ato de caminhar.

Maria Helena vem, em sua trajetória de vida, afirmando esses caminhos e seu compromisso com as mudanças, pois entende que o homem, a sociedade, a psicologia, a educação, a política etc. estão sempre sendo, sempre se fazendo, sempre objetivando e sendo objetivados. Por isso, renuncia aos modelos, às identidades, às permanências, às homogeneidades, às unidades e indissolubilidades e afirma a potência daqueles considerados fracassados e faltosos.

Em nossa história, a ideia de uma sociedade saudável, livre de perigos e disfunções atravessou os séculos XIX e XX; ainda hoje continua presente adquirindo contornos diversos em cada momento. Maria Helena nos aponta como, de um modo geral, as intervenções dos chamados especialistas acabam seguindo essa direção de normatização, de disciplinamento através do estabelecimento de regras e condutas ideais consideradas como as verdadeiras, corretas e universais. A partir da lógica capitalística de vida, estabelece-se o que é bem e mal, certo e errado, regular e irregular, normal e anormal dentre tantas outras dicotomias e binarismos produzidos por essa lógica hegemônica.

Há, portanto, normas sociais que atravessam os mais diferentes âmbitos, legitimando/fortalecendo uma determinada forma de ser, agir, pensar, perceber e sentir; uma determinada forma de viver. 
O que aqui afirmamos leva-nos para o campo das invenções e, por isso, dos desafios. Esses territórios da psicologia e da educação são assumidamente políticos como quaisquer outros em que as lutas se fazem cotidianamente apesar dos "pequenos assassinatos". Ao entendermos o homem, a sociedade, a psicologia, a educação, a política, dentre outros, como objetos produzidos historicamente que não se opõem, mas se atravessam permanentemente, "estamos afirmando uma relação com o tempo - acontecimento, sempre provisória e múltipla, produções de devires, devir-a-ser, de fluxos mutantes" (Coimbra \& Leitão, 2003, p. 10).

Maria Helena Souza Patto, através de sua importante obra, sua fundamental contribuição à psicologia e à educação, tem nos alertado para algumas artimanhas desses tempos ferozes e "sombrios do capitalismo atual". Seus estranhamentos e desnaturalizações nos fazem lembrar do poeta pantaneiro, Manoel de Barros, que nos afirma:

É preciso transver o mundo,

Isto seja:

Deus deu a forma. Os artistas desformam.

É preciso desformar o mundo.

Tirar da natureza as naturalidades.

Fazer cavalo verde, por exemplo.

Fazer noiva camponesa voar - como em Chagall.

Agora é só puxar o alarme do silêncio.

Que eu saio por aí a desformar. (Barros, 1997, p. 75)

\section{Practice of Questioning Normality, Indignation and Resistance}

Abstract: The present text points out some of the important contributions made by Maria Helena Souza Patto to Psychology and Education in our country, especially through her latest book Exercises of Indignation. It is stated in her work not only the competent and caring researcher, the requested and respected professor, but also the altruistic, friendly, receiving and indignated woman, that had always questioned what was usually being considered as normal. It is possible to visualize the many "Marias" presented in this article by one of her students in USP Post-Graduation in 1988. It is especially prominent in this text the daily practice of resistance that the writings of Maria Helena emphasize. Resistance, not as mere reaction, but as creation, production of rupture, affirmation of other logics and other realities. This is one of the many "Marias" presented in this work.

Keywords: Resistance. Psychology and Education. Multiplicity. Indignation. 


\section{Pratiques d'étonnement, indignation et résistance}

Résumé: Cet article souligne quelques-unes des contributions les plus importantes faites par Maria Helena Souza Patto pour la psychologie et la éducation dans notre pays, notamment à travers son dernier livre Exercícios de Indignação. Ce livre montre que l'auteur est un chercheur compétent et prudent, mais aussi une femme solidaire, indignée, sympathique et chaleureuse, qui demande, s'étonne et met à l'analyse ce qui a été considéré comme naturel. Nombreuses et multiples Marias sont présentées ici par une de ses étudiantes diplomées en I'Université de São Paulo en 1988. Ce travail met en relief la pratique quotidienne de résistance que les écrits de Maria Helena soulignent. Résistance, pas comme simple réaction, mais comme la création, la production de ruptures et l'affirmation d'autres logiques, autres réalités. II s'agit d'un des multiples Marias ici presentées.

Mots-clés: Résistance. Psychologie et éducation. Multiplicité. Indignation.

\section{Prácticas de extrañamiento, indignación y resistencia}

Resumen: Este texto señala algunas de las importantes contribuciones hechas por Maria Helena de Souza Patto para la Psicología y la Educación en Brasil, en particular a través de su último libro Exercícios de Indignação. Este libro muestra no solo la investigadora competente y cuidadosa, la profesora respetada y solicitada, sino también una mujer solidaria, amiga, cálida e indignada que pregunta, extraña y pone en cuestión lo que se considera como natural. Son muchas y múltiples Marias que aquí se presenta por una de sus estudiantes de Posgrado de la Universidad de São Paulo en 1988. En este texto, se destaca que los escritos de Maria Helena insistan en la práctica de la resistencia cotidiana. La resistencia es entendida no como una mera reacción, sino como la creación, la producción de rupturas y la afirmación de otra lógica y de otras realidades. Esta es una de las muchas Marias aquí presentes.

Palabras clave: Resistencia.Psicología y Educación. Multiplicidad. Indignación. 


\section{Referências}

Barros, M. (1997). As lições de R. Q. In M. Barros, Livro sobre nada (p. 75). Rio de Janeiro: Record.

Basaglia, F. (1985). A instituição negada:relato de um hospital psiquiátrico. Rio de Janeiro: Graal.

Coimbra, C. M. B., \& Leitão, M. B. de S. (2003). Das essências às multiplicidades: especialismo psi e produções de subjetividades. Revista Psicologia \& Sociedade, 15(2), 6-17.

Deleuze, G. (2002). Espinoza, filosofia e prática. São Paulo: Escuta.

Foucault, M. (1982). Michel Foucault, uma entrevista. Recuperado em 14 de fevereiro de 2007, de www.unb.br/ge/tef

Foucault, M. (1979). Os intelectuais e o poder:conversa entre Michael Foucault e Gilles Deleuze. In M. Foulcault, Microfísica do poder (pp.69-78). Rio de Janeiro: Graal.

Patto, M. H. S. (2010). Exercícios de indignação: escritos de indignação e psicologia. São Paulo: Casa do Psicólogo.

Patto, M. H. S. (1984). Psicologia e ideologia: uma introdução crítica à Psicologia Escolar. São Paulo:T. A. Queiroz.

Patto, M. H. S. (1990). Produção do fracasso escolar: histórias de submissão e rebeldia. Tese de Livre Docência, Instituto de Psicologia, Universidade de São Paulo, São Paulo. 
Cecília Maria Bouças Coimbra, Psicóloga, Professora Adjunta da Universidade Federal Fluminense. Fundadora e Presidente atual do Grupo Tortura Nunca Mais. Endereço para correspondência: Praia de Botafogo, 22/502 - Botafogo. Rio de Janeiro, RJ, Brasil.CEP:22250-040. Endereço eletrônico:gtnm@alternex.com.br

Recebido: $12 / 11 / 2010$

Aceito: 04/04/2011 